\title{
Práticas restaurativas de assistência educacional do programa novos rumos na execução penal
}

\section{Restorative practices of educational assistance of the program new directions in the criminal execution}

\begin{abstract}
Aluísio Azevedo Júnior (unilivreira@outlook.com)*; Fábio Wellington Ataíde Alves (fabioalves@tjrn.jus.br)**; Guiomar Veras de Oliveira (guiomarveras@tjrn.jus.br)**; Nadja Maria de Lima Costa (nadja.costa@ifrn.edu.br)*** * Serviço Nacional de Aprendizagem do Cooperativismo, ** Tribunal de Justiça do Rio Grande do Norte,***Instituto Federal de Educação, Ciência e Tecnologia do Rio Grande do Norte
\end{abstract}

\begin{abstract}
Resumo
O presente texto tratará da concepção e das ações pedagógicas, implementadas pelo Serviço Nacional de Aprendizagem do Cooperativismo (SESCOOP), consubstanciadas em Acordo de Cooperação Institucional, firmado com o Tribunal de Justiça do Rio Grande do Norte, estado federativo brasileiro. No âmbito do projeto denominado "Autores no Cárcere: Restauração pela Escrita", tais iniciativas objetivam conceder assistência educacional a propensos escritores-educandos, encarcerados em unidades prisionais. Representam possibilidades de restauração, reinserção e inclusão social. Fomentam o diálogo entre apenados e sociedade, em espaços socioeducativos, pela Escrita Restaurativa. Buscam a humanização do cárcere, enquanto instigam a consciência crítica das pessoas, numa perspectiva de interculturalidade.
\end{abstract}

Palavras-chave: cárcere, educação, justiça restaurativa, literatura, interculturalidade.

\begin{abstract}
The present text deals with the conception and pedagogical actions implemented by the National Cooperative Learning Service (SESCOOP), embodied in an Institutional Cooperation Agreement signed with the Court of Justice of Rio Grande do Norte, a Brazilian federal state. In the scope of the project called "Authors in the Prison: Restoration by Writing," these initiatives aim to grant educational assistance to prose writers-students, imprisoned in prisons. They represent possibilities for restoration, reinsertion and social inclusion. They encourage the dialogue between imprisoned people and society, in socio-educational spaces, by the Restorative Writing. They seek the humanization of the prison, while instigating the critical awareness of the people, in a perspective of interculturality.

Keywords: prison, education, restorative justice, literature, interculturality.
\end{abstract}

\section{Ambiência institucional e normativa}

O projeto "Autores no Cárcere: Restauração pela Escrita" foi implementado pelo Programa Novos Rumos na Execução Penal, no âmbito do Sistema Penitenciário. Em provimento próprio, emitido em 06 de abril de 2017, o Poder Judiciário do Rio Grande do Norte, através da sua Corregedoria Geral de Justiça, instituiu a remição pela Escrita Restaurativa. Assegurou-se ao custodiado, dessa forma, como parte da assistência educacional na Execução Penal, possibilidade de acesso a atividades de produção literária. Garantida sua denominação de autor, enquanto praticante e candidato aos benefícios instituídos. Por critério estabelecido, o autor poderá apresentar seus textos literários para avaliação, observados os objetivos propostos pela Justiça Restaurativa, além da estética, aderência ao tema e fidedignidade. Em caso de aprovação, uma vez por mês, fará jus à remição de 04 (quatro) dias de sua pena.

Acordo específico de cooperação institucional e técnica, firmado entre o Tribunal de Justiça e a Organização das Cooperativas do Estado do Rio Grande do Norte (OCERN), conta com a especial interveniência do Serviço Nacional de Aprendizagem do Cooperativismo (SESCOOP-RN). Destaque-se, então, a participação da referida entidade em apoio aos objetivos constituídos. Especialmente, por se ocupar do ensino, formação e qualificação cooperativista. Aporta ao Projeto "Autores no Cárcere: Restauração pela Escrita" importantes colaborações teóricas. Concepções, úteis ao processo de planejamento. E contribuições práticas referentes ao processo de ensino e aprendizagem, por meio de ações pedagógicas efetivas. Sua atuação confirma predisposição, em respeito aos princípios cooperativistas, à integração com a sociedade; preocupação com as mazelas sociais; direcionamento de seus trabalhos às pessoas em situação de vulnerabilidade. O Sistema Cooperativo, assim, colabora para a transformação da sociedade, visando sustentabilidade econômica, social e ambiental, no cumprimento dos dezessete Objetivos de Desenvolvimento Sustentável (ODS), instituídos pela Cúpula das Nações Unidas.

\section{Ambiência conceitual}

A Justiça Restaurativa representa o cerne conceitual de nossas abordagens. Howard Zehr a define como um processo que envolve todos os que têm interesse em uma 
determinada ofensa. Coletivamente, pensam uma estrutura alternativa que identifique necessidades e obrigações decorrentes dessa ofensa. Promovem o restabelecimento das pessoas e se preocupam com a reparação dos danos.

Justiça Restaurativa visa à conscientização sobre os fatores que motivam a violência, alteração da percepção, do significado que a sociedade tem sobre o delito, e as consequências da transgressão. Entre os interessados estão os que sofreram diretamente o impacto pelo ato, mas também pessoas da comunidade. A comunidade é entendida como grupo de pessoas que interagem com as partes, bem como, as que se importam com a ofensa. Neste ultimo grupo, incluem-se aqueles que se preocupam com a segurança, os direitos humanos e o bem-estar de seus membros, em geral. Há predominância de três modelos para a prática de Justiça Restaurativa: (1) encontros de vítima e ofensor; (2) conferências de grupos familiares; e (3) Círculos Restaurativos. Enfatizemos, especificamente quanto aos Círculos, suas inúmeras aplicações, tais como: determinar sentenças para processos criminais; lidar com conflitos em ambientes específicos; construção de um ideário pacificador, e processos de diálogo comunitário.

Sobre o Reconhecimento e a Justiça, deve-se atentar para os sentidos intimamente ligados, sendo o primeiro algo como uma precondição para o segundo. A questão do reconhecimento aparece como subjacente ao conceito da Justiça Restaurativa, que pede para envolvidos em uma questão, conflito ou crime, se reconhecerem como humanos, em igual condição de direitos e deveres. Pelikan (2005) afirma que o reconhecimento diz respeito à interação, ao diálogo. Reconhecer significa perceber e compreender as palavras e ações da outra pessoa.

$O$ perdão pode consistir em alternativa, escolha pessoal, um ir para outro lugar dentro de si, certo de que o passado não mais determina negativamente o presente. A única solução possível para o problema da irreversibilidade - a impossibilidade de se desfazer o que se fez - é a faculdade de perdoar (Arendt, 2008).

Perdão e promessa são exigências da liberdade e da pluralidade, para construirmos uma comunidade, uma humanidade com pequenas ilhas de previsibilidade. Garantem a convivência humana entre iguais, em liberdade.

Outra forma de expressar o perdão, no aspecto político, é dizer que o perdão não esquece, não incita à impunidade, mas transforma a culpabilidade moral em responsabilidade. Graças ao perdão, é possível optar por um modo de atuação no qual a violência deixa de ser o motor secreto da ação. O perdão é uma tolerância, a consciente abstenção de realizar algum comportamento autorizado pelo sistema normativo. "Quem tolera, se abstém de proibir; quem perdoa, se abstém de castigar." (Mate, 2008, p. 60.)

\section{Ambiência pedagógica}

A implementação do Projeto pressupõe utilização de alguns princípios de Literacia Emergente, mesmo considerando-se que o público abrangido não seja infantil. Trata-se de uma caracterização, por ser um processo holístico, direcionada por competências cognitivas e afetivas, na construção de significado, no desenvolvimento da comunicação. Enquanto processo desenvolvimental, respeita e se adequa aos níveis cognitivos e psicossociais das pessoas. A prossecução dos objetivos pressupõe diferentes e complementares abordagens (Commission Scolaire Marie-Victorin, 2004). Dentre as quais, destacamos: (1) cognitiva, através de atividades e de práticas que encorajem conflitos cognitivos; (2) interativa, através de interações significativas, contextuais e com sentido; (3) semiótica, através de atividades, de práticas e de interações que promovam a construção do significado.

Decerto, a implementação de práticas tipicamente voltadas para a literacia emergente, fundados num conjunto de atividades e de ações pedagógicas, permitirá ancorar, promover e encorajar a aquisição de conhecimentos, de capacidades e de atitudes essenciais para a mestria da linguagem escrita.

\section{Grupos de aprendizado da escrita restaurativa}

No âmbito do projeto denominado "Autores no Cárcere: Restauração pela Escrita", as atividades de assistência educacional a escritores-educandos serão empreendidas, em duas frentes. Constituídos dois grupos específicos de aprendizado.

De um lado, os escritores-educandos das unidades carcerárias, apenados, em especial, mantidos nas estruturas da APAC - Associação de Proteção e Assistência Carcerária, beneficiários e candidatos à remição de pena, através da escrita restaurativa. Pessoas distanciadas da educação formal, pouco sensíveis à literatura; em alguns casos, ainda desconhecedores dos códigos de escrita e leitura. Portanto, no primeiro grupo de aprendizado, será necessária, ainda, uma divisão em subgrupos, o que permitirá melhor aplicação de ferramentas pedagógicas apropriadas. Especificamente, subgrupos de alfabetizados e não-alfabetizados, em princípio. De tal forma, possibilitam-se a prática da oralidade, a sensibilização literária, o desenvolvimento de uma Literacia Emergente, o aprendizado da arte literária, o fazer da escrita criativa, de uma forma personalizada e eficaz.

De outro lado, integrantes da Comunidade de Suporte, assim denominados por Barton (2003) os que poderiam ser pessoas importantes na vida da vítima e do agressor, que mereceriam seu respeito e sua confiança. Estas comunidades de suporte, equilibradas e empoderadas, são fundamentais ao sucesso, também para conter a vitimização dos envolvidos.

Rössner (2000) confirma ser importante fazer a diferenciação entre o ato e a pessoa. Se realizada com exito, pode abrir possibilidades ao ofensor. Tal diferenciação suscita responsabilização pelo crime e, ao mesmo tempo, distanciamento, através da restauração, em relação à vítima e à comunidade.

Em visão alargada, que aproveitamos, no parecer de Winter (2004), a comunidade ainda pode ser o contexto social, uma vez que a restauração é um processo de justiça curativa. A comunidade tem forte importância, no sentido de contribuir para a cura social. Capaz de propiciar uma estrutura protetora para a vítima, 
consciente de que o mal que se manifestou no crime relaciona-se, potencialmente, com a natureza humana. Todos os participantes da comunidade humana sentem-se atraídos e repelidos por esse mal. O ofensor é um ser humano que se tornou diferente de todos os outros e, ao mesmo tempo, continua tão igual a todos; tão igual àquilo que todos podem vir a ser.

\section{Círculo de planejamento}

A etapa de planejamento constitui-se de várias ações, que envolvem atores dos processos desencadeados no Projeto, visando ao desenvolvimento da escrita criativa e restaurativa.

Ateliês pedagógicos, com a participação de professores, pedagogos, psicólogos, literatos e escritores colaboradores, constituem ferramentas de planejamento adotadas pelo SESCOOP-RN. Suas realizações objetivam a formatação de proposta sistêmica e metodológica, no âmbito do trabalho de coordenação pedagógica do Projeto. O resultado esperado dos ateliês será um planejamento tático-operacional, devidamente formalizado, que considere as necessidades de currículo, formação e qualificação dos docentes e instrutores, dos facilitadores; definição de objetivos, ementas, conteúdos programáticos, referências bibliográficas, metodologias, cronogramas, materiais e equipamentos necessários; estrutura dos planos de aula, descrição das ferramentas de apoio e dinâmicas grupais; sistemáticas de monitoramento e avaliação.

Um diagnóstico situacional identificará a estrutura física e organizacional dos presídios; o perfil das suas populações carcerárias. Destaque para a estrutura da APAC, enquanto ambiente modelar. Esse diagnóstico apresentará avaliação dos educandos, evidenciando desafios do processo de prevenção individual, oportunidades e perspectivas identificadas.

Os planos operacionais, especificamente, serão concluídos, nas etapas práticas, com a participação dos diversos grupos de aprendizado da escrita restaurativa, consideradas as colaborações dos escritores-educandos, dos comunitários de suporte, e docentes das instituições de ensino parceiras.

\section{Escrita restaurativa - problematização e práticas pedagógicas}

Os sentidos de justiça e punição são emblemáticos. A punição faz sofrer alguém intencionalmente, impor algo desvantajoso, oneroso. Pode ser resposta social e política a uma conduta considerada não desejada, ofensiva ou criminosa. Seu conteúdo impõe ao punido a vontade alheia. Contudo, qual é a capacidade dessa imposição, dessa submissão reforçar a responsabilidade de um sujeito e a sua cidadania? A vítima, representada pelo Estado, tem o direito de impor um castigo sobre quem a prejudicou. Pune-se o ato criminoso, na proporção do crime. Eis a lei da justiça que retribui, em forma de pena e punição, na devida proporção, a cada um, o que lhe deve. Caminho de reconhecimento público da vítima, como ser ofendido e humilhado, excluído do regime da reciprocidade, pelo dano que o crime lhe provocou.

Os teóricos McCold e Wachtel (2003) desenvolveram a Janela de Disciplina Social, que combina controle, limitando ou influenciando os outros; e apoio, que cuida, encoraja ou assiste.

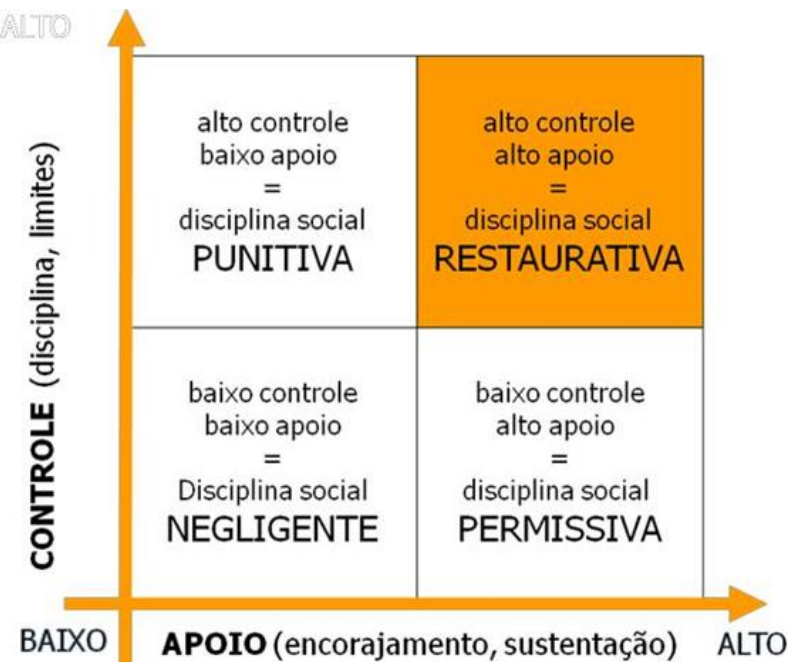

Figura 1: Janela de Disciplina Social, de McCold e Wachtel.

A abordagem punitiva ou retributiva, com alto controle e baixo apoio, tende a estigmatizar as pessoas, rotulando-as de forma negativa. As respostas são reações ao transgressor, punindo e reprovando, mas permitindo pouco envolvimento ponderado e ativo do mesmo. A Permissiva ou Reabilitadora, com baixo controle e alto apoio, tende a proteger as pessoas das consequências de suas ações erradas. Faz tudo pelo transgressor, pedindo pouco em troca e criando desculpas para as transgressões. A abordagem negligente é de baixo controle e baixo apoio, caracterizada pela indiferença e passividade e nada faz em resposta à transgressão. Por fim, a abordagem restaurativa, com alto controle e alto apoio, confronta e desaprova as transgressões, encoraja o transgressor a envolver-se conscientemente com a sua comunidade, participando diretamente do processo de reparação e prestação de contas.

Os desafios da Justiça Restaurativa passam pela substituição da palavra punição por responsabilização e restauração, por alcançar a sensação de reconhecimento do ofensor, ou a quem foi imputada uma culpa. Por levar à responsabilização, mais do que da punição. Especialmente, os processos restaurativos precisam fortalecer os laços de solidariedade na sociedade, considerando a possibilidade holística do perdão, a formação de uma consciência crítica sobre justiça e punição, desencarceramento e ressocialização.

\section{Círculo prático de escrita restaurativa}

A prática educacional será encetada pela consolidação planejadora, mediante elaboração participativa do plano operacional de atividades.

Quanto à organização, os círculos práticos de escrita restaurativa serão coordenados por um facilitador, voluntário capacitado em técnica autocompositiva e consensual, responsável pela vigilância dos parâmetros da Justiça Restaurativa. A regra do processo de remição penal prevê a possibilidade de eleger-se, dentre os 
apenados, a figura do autor-facilitador, dotado de habilidades e competências, capacitado a orientar seus colegas, e participar dos círculos restaurativos.

Ações pedagógicas serão empreendidas, objetivando conceder assistência educacional a propensos escritores-educandos, encarcerados em unidades prisionais. Bem como, promover a formação de espírito crítico e conscientização da sociedade, em relação ao papel da Justiça, à organização do Sistema Carcerário, e aos processos restaurativos de reinserção social de apenados. Permitem desdobramentos, possibilidades de restauração, reinserção e inclusão social, ao tempo em que fomentam o diálogo entre grupos de apenados e espaços educativos. Constituem-se linhas de acesso a condições mais humanizantes, em benefício das pessoas privadas de liberdade, numa perspectiva de interculturalidade, mediante adentramento ao mundo das letras e das artes. Nesse intento, conformam-se círculos integradores e restaurativos, necessariamente interconectados e constituídos por seus diversos atores. Executam-se processos voltados para a sensibilização literária dos educandos, oficinas de produção literária, práticas de criação e redação. Outras atividades de revisão e conclusão dos textos culminam com apresentação de painéis expositores pelos autores-educandos. Seguem-se práticas de produção textual, revisão, conclusão dos textos.

\section{Círculo avaliativo e de reação às práticas restaurativas}

Numa terceira etapa, está considerada a adoção das práticas continuadas de produção textual, e a validação dos trabalhos realizados, com o fim de sedimentar os processos de escrita restaurativa.

Por suas características, ao tempo em que transcorre o processo de avaliação, também se consubstancia círculo restaurativo. Notadamente, a partir da palavra expressa, da responsabilização ativa e da reparação dos danos. Para fins de registro, deve-se extrair uma memória formal, destinada ao processo de execução penal. Podem ser instaurados outros círculos específicos, fora do processo avaliativo, dos quais participarão vítimas, ofensores, interessados e membros da rede de garantias, obedecidos parâmetros da Resolução 225 do Conselho Nacional de Justiça.

Por fim, no tocante ao acompanhamento e avaliação, definem-se medidas de desempenho do Projeto. Réguas de aferição são fundamentais à quantificação e à avaliação qualitativa das ações educacionais empreendidas. Numa visão geral dos Círculos Integradores e Restaurativos, são definidos, então, modelos de avaliação do texto literário concluído; documento de certificação ou devolução; formas de registro da participação dos autores-educandos; medidas de desempenho do Projeto; avaliação de reação dos educadores e educandos; mecanismos estruturais de controle social, e as condições necessárias à realimentação dos processos.

\section{A cidadania e o discurso}

A cidadania tem a ver com o público, o plural e o direito entre iguais. Para Arendt (2008), público é aquilo que pode ser falado, discutido e ouvido por todos. Nos procedimentos da Justiça Restaurativa, através da comunicação dos diversos relatos e verdades, colocam-se em público coisas, muitas vezes experimentadas na privacidade ou na intimidade. Estas, trazidas à esfera pública, assumem condição de nova realidade. A presença de outros, que veem o que vemos e ouvem o que ouvimos, nos garante a realidade do mundo e de nós mesmos. De certo modo, nos confirma no mundo.

Assim, quando uma questão ou um conflito é trazido a público, passa a existir para a coletividade e, somente assim, torna-se possível uma ação política. A pluralidade, com seu duplo aspecto de igualdade e diferença, é condição básica da ação e do discurso, pois, se não forem iguais, os humanos serão incapazes de compreender-se entre si.

Profunda igualdade, enquanto humanos, e profundo respeito pelas diferenças. Na ação e no discurso, os humanos se manifestam enquanto humanos que, na condição de sujeitos capazes, podem conquistar seus direitos. Os procedimentos da Justiça Restaurativa podem, no caso ideal, criar ambiente que permita a singularidade de cada envolvido e a divergência de cada contexto, enquanto se procuram respostas adequadas. A vida sem discurso é literalmente morta para o mundo, deixando de ser uma vida humana.

A construção da cidadania pede o rompimento de diversos silêncios e pede, ao mesmo tempo, a polifonia divergente da voz dominante. Uma vez que a violência é muda e o oposto da violência é o poder (Arendt, 1994), a questão do empoderamento através do exercício da palavra é extremamente importante, na construção e no exercício da cidadania.

O círculo restaurativo permite e, de certa forma, convida os envolvidos, através do exercício da fala, a mostrar quem são. Revelam-se as suas identidades pessoais e singulares. Quando as pessoas partilham suas histórias de dor e erros, deixando cair camadas protetoras, revelam-se como seres humanos (Pranis, 2010).

O empoderamento e o exercício da palavra são formas de lidar com a liberdade de sermos humanos, lidar com nossa pluralidade, também com nossa imprevisibilidade. $\mathrm{O}$ empoderamento possibilita o mecanismo de confrontação com os próprios atos e com os do outro, sua identidade, suas necessidades e seus interesses. Faz parte de uma cidadania emancipada assumir a responsabilidade pelo bem e pelo mal que foram feitos, uma vez que isso é uma possibilidade de nossa condição humana.

\section{Considerações finais}

Além dos sentidos da punição e do justo, as práticas desenvolvidas no projeto "Autores no Cárcere: Restauração pela Escrita" fomentam a ideia do perdão, como ação publica. Neste sentido, o perdão, de certa forma, suspende a retribuição determinada pelo senso comum e pela instituição justiça. Por isso é tão suscetível à crítica, quando aplicado, exatamente, em nome desta mesma justiça. A renúncia intrínseca ao perdão, possivelmente, parte de uma consideração moral de que o 
ser humano, para conviver com outros, precisa enfatizar a própria responsabilização por seus atos, fazer promessas para o futuro e possibilitar uma vivência em comum, antes que punir.

Colocar-se no lugar do outro parece ser um recurso importante nos procedimentos da Justiça Restaurativa, pois permite construção da verdade, abertura para o diálogo, alteridade e coragem para assumir seus atos.

Por uma cultura de paz, perdão e justiça. Em cada um dos diversos círculos programados, mediante envolvimento de encarcerados, dos grupos de controle escolhidos, dos diversos atores, a prática da Escrita Restaurativa servirá à construção do senso comunitário, resolução de conflitos, reintegração, celebração de uma nova sociedade. Um Círculo de Paz (Pranis, 2010), baseado no exercício do diálogo, na compreensão, no restabelecimento, na plena restauração da condição humana.

\section{Referências}

Arendt, H. (1994). Sobre a violência. Rio de Janeiro: Relume-Dumaré.

Arendt, H. (2008). A condição humana. Rio de Janeiro: Forense Universitária.

Barton, C.K.B.(2003). Restorative Justice: the empowerment model. Sydney:Hawkins Press.

Commission Scolaire Marie-Victorin (2004). Hand in Hand: Emergent Literacy from A to Z. Recuperado em 10 de julho de 2017, de: http://www.education.gouv.qc.ca/fileadmin/site_web/ documents/dpse/educ_adulte_action_comm/Hand_in_ Hand_emergent_literacy_from_A_to_Z.pdf

Mate,R.(2008).Justicia de las victimas. Terrorismo, memoria, reconciliación. Barcelona:Anthropos.

McCold, P. \& Wachtel, T. (2003). Uma teoria de justiça restaurativa. Trabalho apresentado no Congresso Mundial de Criminologia, Rio de Janeiro, 2003. Recuperado em 10 de julho de 2017, de: <http://gajop.org.br/justicacidada/wp-content/uploads/ Em-Busca-de-um-Paradigma-Uma-Teoria-de-Justi\%C 3\%A7a-Restaurativa.pdf $>$..

Pelikan, C. (2009). Die Möglichkeiten und die Bedingungen einer wirksamen Stärkung (Mächtigung) der Opfer von Gewalt in Paarbeziehungen durch den Außergerichtlichen Tatausgleich. Wien: Forschungsbericht Neustart, Institut für Rechts und Kriminalsoziologie. Recuperado em 10 de julho de 2017, de: 〈www.irks.at/downloads/Oper_ATA.pdf〉.

Pranis, K. (2010). Processos Circulares. São Paulo: Palas Athena.

Rössner, D. (2000). Ergebnisse und Defizite der aktuellen TOA - Begleitforschung - Rechtliche und empirische Aspekte. In: Gutsche, Günter; Rössner. Täter - Opfer - Ausgleich: Beiträge zur Theoria, Empirie und Praxis. Mönchengladbach: Forum Verlag Godesberg $\mathrm{GmbH}$.

Winter, F.(2004). Der Täter-Opfer-Ausgleich und eine Vision Von einer "heilenden" Gerechtigkeit. Worpswede: Amberg Verlag.

Zehr, H. (1990). Changing Lenses: a New Focus for Crime and Justice. Ontario: Herald Press,
Zehr, H. (2008). Trocando as lentes. Um novo foco sobre o crime e a justiça. São Paulo: Palas Athena. 